\title{
POR UMA REFLEXÃO CONSTITUCIONALMENTE ADEQUADA DA APLICAÇÃO DAS NORMAS NO DIREITO PENAL: OS RISCOS DA DISCRICIONARIEDADE NO CONTEXTO DA INSIGNIFICÂNCIA
}

Álisson Silva Costa ${ }^{1}$

\section{RESUMO:}

Este artigo procura refletir a respeito da adequada compreensão dos princípios no campo do Direito Penal. Sendo uma das áreas do Direito mais diretamente ligada com a limitação de Direitos e Garantias Fundamentais, a interpretação constitucionalmente adequada dos princípios jurídicos aparece como fundamental para a estrutura do que se pretende com um Estado Democrático de Direito. Embasada nas reflexões teóricas de autores não positivistas, bem como à postura observada em pronunciamentos decisórios dos Tribunais Superiores, com destaque para o Supremo Tribunal Federal -STF, a pesquisa, descritiva-explicativa, estabelece uma postura conclusiva de que a discricionariedade judicial continua presente em vários discursos de fundamentação, estando, não raras vezes, associados ao sustentáculo dos argumentos de política.

Palavras-chave: Insignificância; Princípios; Interpretação; Discricionariedade; Integridade.

\section{FOR A CONSTITUTIONALLY ADEQUATE REFLECTION OF THE APPLICATION OF NORMS IN CRIMINAL LAW: THE RISKS OF DISCRETION IN THE CONTEXT OF INSIGNIFICANCE}

\begin{abstract}
:
This article seeks to reflect on the proper understanding of the principles in the field of Criminal Law. As one of the areas of Law most directly linked to the limitation of Fundamental Rights and Guarantees, the constitutionally adequate interpretation of legal principles appears as fundamental to the structure of what is intended with a Democratic State of Law. Based on the theoretical reflections of non-positivist authors, as well as the position observed in decision-making decisions of the Superior Courts, with emphasis on the Federal Supreme Court (STF), the descriptive-explanatory research establishes a conclusive posture that judicial discretion remains present in Several discourses of reasoning, and are not infrequently associated with the support of political arguments.
\end{abstract}

Keywords: Insignificance; Principles; Interpretation; Discretion; Integrity.

\footnotetext{
${ }^{1}$ Doutor em Teoria do Direito pela PUC-Minas/Faculdade Mineira de Direito. Mestre em Teoria do Direito pelo Programa de Pós-Graduação em Direito da Faculdade Mineira de Direito da Pontifícia Universidade Católica de Minas Gerais. Foi Bolsista da CAPES durante o mestrado. Especialista em Docência do Ensino Superior pela UCAM - Universidade Cândido Mendes. Graduação em Direito pela Faculdade Mineira de Direito da Pontifícia Universidade Católica de Minas Gerais.
} 


\section{Prolegômenos ao desafio da busca de uma adequada compreensão das normas no Direito Penal}

O Direito, enquanto construção histórica e social, aparece como uma das ordens normativas mais tradicionais no contexto social. Enquanto direcionada para a estabilização das expectativas comportamentais dos sujeitos em interação social, uma das áreas do saber jurídico, qual seja, o Direito Penal, aparece como sendo a de maior ingerência na esfera pessoal do indivíduo, em razão da possibilidade de limitação de alguns Direitos e Garantias Fundamentais, conforme limites estabelecidos no Texto Constitucional.

Considerando a construção científica do Direito, sua estrutura aparece alicerçada em normas jurídicas que, classificadas conforme variados critérios da Literatura Jurídica, fornecem elementos satisfatórios para a compreensão do Direito.

A partir do enfraquecimento das ideias desenvolvidas no contexto do Positivismo Jurídico, uma das espécies normativas, os princípios jurídicos, ganharam maior relevância no momento da aplicação do direito, especialmente como determinantes para a solução dos casos jurídicos, sejam eles marcados ou não por acentuada complexidade.

No âmbito da aplicação, nos moldes constitucionalmente adequados, o agente julgador responsável pela confecção do pronunciamento decisório precisa observar os limites e possibilidades da compreensão do e no Direito. Diante disso, considerando a liberdade atribuída, por lei, aos juízes, em qual sentido a construção de um provimento encontra harmonia na utilização da discricionariedade?

Pois bem. O tema central da presente reflexão crítica consiste na busca por uma adequada compreensão da aplicação das normas no contexto do Direito Penal, com destaque para a verificação da incidência da norma da Insignificância na apreciação de determinadas práticas de ilícitos penais.

A partir dessa pretensão, a expectativa é a de que a discricionariedade seja confirmada como um risco às pretensões de um Estado Democrático de Direito que, ainda que em construção, apresenta todo um compromisso com a história institucional do Direito.

Via de consequência, a busca por uma adequada compreensão das normas no Direito Penal abre espaço para o afastamento de construções discricionárias no Direito e 
pretende confirmar a plausibilidade da adoção de raciocínios, como aquele do Direito como Integridade, tanto no contexto da Legislação, como também e, talvez principalmente, no contexto da Jurisdição.

O primeiro movimento pretendido na presente investigação adota como metodologia, a pesquisa descritiva-explicativa, é dizer, adota como sustentáculo, a partir da Literatura Jurídica, o recorte da construção teórica da normatividade no contexto jurídico, alcançando duas linhas, quais sejam, a especificação e a explicação da insignificância enquanto norma.

No segundo momento, a pesquisa, tomando por base análises feitas dos pronunciamentos decisórios dos tribunais superiores a respeito da temática da insignificância, tem o intuito de verificar, diante de tais manifestações, a adequação de tais pronunciamentos, considerando linhas fundamentadoras, como a do Direito como Integridade.

Para tanto, considerando as possíveis teses a respeito do assunto, o raciocínio dialético será utilizado, bem como o indutivo, em razão da verificação da possível ampliação da fundamentação dos pronunciamentos decisórios, em caso de sua coerência.

\section{A centralidade no contexto do Não Positivismo.}

Dentre outras possíveis posturas ${ }^{2}$ do Não Positivismo $^{3}$, a chamada "reabilitação" dos princípios no contexto da interpretação judicial aparece como destaque. Com isso, eles, os princípios, estão "elevados agora à condição de protagonistas e não mais confinados a um papel de mero coadjuvantes ou figurantes como na etapa positivista tradicional." (DINIZ; MAIA, 2009, p. 653).

$\mathrm{Na}$ dinâmica jurídica brasileira é muito comum a utilização de princípios jurídicos na discussão de resolução das questões jurídicas. No entanto, por vezes, tais manifestações não expressam coisa alguma, uma vez que ficam reduzidas à retórica. $\mathrm{O}$ risco do mencionado movimento é exatamente a adoção de uma "roupagem magnífica (os princípios), para opiniões discutíveis.” (MORVAN, 2012, 1391).

\footnotetext{
${ }^{2}$ Como a atribuição de uma maior importância aos chamados casos difíceis (DINIZ; MAIA, 2009), ou seja, os chamados "hard cases".

${ }^{3}$ Tradicionalmente, muitos autores utilizam a expressão "Pós-positivismo".
} 
Jean Boulanger apresenta uma consideração condizente com a percepção a respeito dos princípios. Para mencionado autor, os princípios aparecem não como exteriores à ordem jurídica positiva, mas antes, como integrantes da mesma e que, portanto, não precisam estar refletidos explicitamente nos textos da lei, cabendo à jurisprudência a limitação de declará-los. (apud GRAU, 2006, p. 155). Esse ponto marca a superação de toda uma preocupação histórica da Literatura Jurídica a respeito da necessária positivação das normas jurídicas para sua validade e consequente vigência.

No contexto da Teoria dos Princípios, Lalande em seu "Vocabulário técnico e crítico da filosofia", apresenta os três sentidos possíveis para o princípio ${ }^{4}$, quais sejam, o ontológico, lógico e normativo.

Em termos jurídicos, a (re)estruturação dos princípios jurídicos acarretaram uma

transformação substancial da noção de Estado de Direito. Doravante, juízes e tribunais, tanto no plano nacional como no internacional, já não podem se limitar a julgar as causas trazidas ao seu conhecimento com base na pura formalidade externa. Eles são obrigados a se pronunciar, justificadamente, sobre a justiça e injustiça da pretensão deduzida em juízo. (RAMOS, 2012, p. 20).

O tradicionalmente denominado "princípio da Insignificância" espécie normativa que tem recebido grande consideração jurídica nos últimos anos, aparece inserido na problemática envolvendo a discricionariedade judicial, além de refletir, quando de sua possível aplicação, o crescimento de casos envolvendo os chamados delitos de bagatela, crescimento muitas vezes associado ao contexto social de marginalização em que muitos cidadãos se encontram.

Influenciado diretamente por orientações de Política Criminal, a Insignificância no contexto do Direito Penal tem aberto grande espaço para incompreensões, que apresentam como geratriz o enfraquecimento da normatividade, bem como o excesso de discricionariedade em sua configuração.

Some-se a isso a descontextualização do campo jurídico-penal no que diz respeito aos chamados "cânones interpretativos", bem como a manutenção do

\footnotetext{
${ }^{4}$ Esse ponto é interessante, uma vez que a palavra princípio, em na etimologia remonta à palavra latina principium: logo, primo, primeiro e capere, tomar. Seu sentido traduz a ideia de um começo, de um início. Em fins do século XVII, a Academia Francesa, por meio de seu dicionário fornece um conjunto de sentidos mais desenvolvido a respeito do termo, segundo nos fala Morvan (2012).

${ }^{5}$ Ainda limitados ao posicionamentos das Escolas tradicionais do pensamento jurídico.
} 
conhecido esquema "sujeito-objeto", esquema ainda presente na dinâmica da filosofia da consciência (Streck, 2010) e que acaba fortalecendo, de maneira arriscada, os poderes do agente julgador.

Certamente que o Direito Penal, nos moldes atuais, busca reduzir sua atuação, especialmente pela crescente confirmação da insuficiência ressocializadora de seus institutos de execução penal. No caso brasileiro, o Constituinte fixou a Dignidade da Pessoa Humana como fundamento da República Federativa do Brasil, tal qual podemos observar no art. $1^{\circ}$, III, do Texto Constitucional (BRASIL, 1988), o que, consequentemente, aumenta ainda mais a ineficácia e descompasso de alguns institutos aplicáveis ao procedimento de excecução criminal.

Por esse motivo, o Direito Penal aparece como alicerçado nos "verdadeiros" princípios informadores da área penal, o Principio da intervenção Mínima e o Princípio da Fragmentariedade. (CAPEZ, 2008; JESUS, 2009), no intuito de atribuir à essa do Direito uma atuação mínima.

É, aliás, neste momento que a Intervenção Mínima aparece preservando a relação entre a "autoridade e a liberdade" (RAMOS, 2012, p. 536), quando harmoniza o "poder punitivo do Estado (jus puniendi) com a garantia de segurança e proteção às liberdades dos cidadãos.” (RAMOS, 2012, p. 536).

O Supremo Tribunal Federal - STF, segue a mesma linha orientadora, ao entender que

\begin{abstract}
O sistema jurídico há de considerar a relevantíssima circunstância de que a privação da liberdade e a restrição de direitos do indivíduo somente se justificarão quando estritamente necessárias à própria proteção das pessoas, da sociedade e de outros bens jurídicos que lhes sejam essenciais. Especialmente nos casos em que os valores penalmente tutelados se exponham a dano - efetivo ou potencial - causado por comportamento impregnado de significativa lesividade. (STF. HC n. 92.463/RS, $2^{\text {a }}$ Turma. Rel. Min. Celso de Mello. Julg. 16.10.2007. DJe, 31 out. 2007)
\end{abstract}

No direito brasileiro, o grande responsável pela primeira abordagem doutrinária da Insignificância foi o professor Francisco de Assis Toledo, que sustentava, em razão da característica de fragmentariedade do Direito Penal, que este não deveria se ocupar de situações envolvendo bagatelas (TOLEDO, 1994). Este argumento é harmônico com a postura adotada por Claus Roxin, quando este reconhece a suficiência de outros meios jurídicos para a resolução de questões jurídicas. Roxin entende que 
onde bastem os meios do direito civil ou do direito público, o direito penal de retirar-se, consequentemente, e por ser a reação mais forte da comunidade, apenas se pode recorrer a ela em último lugar. (ROXIN, 1998, p. 28).

Embora no cenário brasileiro o "princípio" da Insignificância não encontre previsão expressa na Constituição Federal nem tampouco no Código Penal, tanto a jurisprudência, quanto a literatura jurídica têm reconhecido e aplicado o mencionado "princípio". Essa ausência de precisão expressa reforça a necessária preocupação com sua adequada fundamentação.

No entanto, não há coerência em tais atividades, especialmente em termos do respeito para com a história institucional, o que provoca, por vezes, incoerências na própria construção do direito enquanto um complexo harmônico.

\section{A Insignificância no contexto jurídico brasileiro}

Apesar da posição majoritária das consideradas "fontes" do Direito, jurisprudência e doutrina, a pretensão de presente argumentação é a de fixar entendimento de que, considerando a existência de princípios que permitem a configuração do Direito Penal como a ultima ratio, a Insignificância poderia figurar como uma regra jurídica que, enquanto norma, estaria voltada para a regulação de determinada situação, afastando sua incidência em relação a outros contextos.

Como explicado nas aulas introdutórias dos cursos de Direito, no campo jurídico, um princípio apresenta não apenas uma conotação daquilo que "é”, mas daquilo que "deve ser”. Essa conotação precisa resultar daquilo que se espera em termos de um verdadeiro Estado Democrático de Direito, é dizer, a oportunidade de participação dos cidadãos no processo de elaboração normativa, tal qual destacado por autores como Habermas (2003), além da compreensão de que os princípios jurídicos funcionam como "pautas de regulação de conduta, vale dizer, como normas" (CHUEIRI, 2009, p. 261).

Como possível configuração, Roxin admite conceber a insignificância como aquilo que se denomina de "máxima da interpretação típica" (ROXIN, 1972, p. 296), no 
sentido de que cada caso $^{6}$ deveria ser analisado tomando-se por base a interpretação restritiva visto que

Só uma interpretação estritamente referida ao bem jurídico e que atenda ao respectivo tipo (espécie) de injusto deixa claro por que uma parte das ações insignificantes são atípicas e frequentemente já estão excluídas da própria dicção legal, mas por outro lado, como v.g. os furtos de bagatela, encaixam indubitavelmente no tipo: a propriedade e a posse também se veem vulneradas pelo furto de objetos insignificantes, enquanto em outros casos a bem jurídico só é menoscabado se ocorre certa intensidade da lesão. (tradução livre). (ROXIN, 1972, p. 297).

Verifica-se, então que, considerando a possibilidade a existência de respostas correras em Direito Penal, sua construção não é algo já pré-existente; logo, a resposta correta é algo construído de modo argumentativo, motivo pelo qual "não faz sentido em falar de criação de normas jurídicas, isto é, ato discricionário do juiz.” (CHUEIRI, 2009, p. 261).

Em outro sentido, no entanto, não raras vezes a Insignificância é considerada como uma forma de "desafogar" a Justiça, pois

\begin{abstract}
Permite não processar condutas socialmente irrelevantes, assegurando não só que a Justiça esteja mais desafogada, ou bem menos assoberbada, senão permitindo também que fatos nímios não se transformem em uma sorte de estigma para seus autores. Do mesmo modo, abre a porta para uma revalorização do direito constitucional e contribui para que se imponham penas a fatos que merecem ser castigados por seu alto conteúdo criminal, facilitando a redução dos níveis de impunidade. (CORNEJO apud GOMES, 2010, p. 52-53).
\end{abstract}

Mediante uma pesquisa e abordagem de julgados no contexto dos tribunais superiores, com destaque para o Supremo Tribunal Federal - STF, os acórdãos tem destinado à Insignificância a tarefa de funcionar como uma válvula de escape para resolver problemas estruturais do próprio judiciário. A alegação por vezes aparece no sentido de demonstrar que o Estado tem movido "toda sua dispendiosa engrenagem para apurar fatos insignificantes e juridicamente irrelevantes, mas que, em suma, exigem gastos similares aos do processamento de feitos que realmente refletem algum interesse social.” (DIAS JUNIOR, 2005, p. 272).

\footnotetext{
${ }^{6} \mathrm{O}$ que acaba reforçando a possibilidade de considerarmos a Insignificância como uma regra aplicável ou não a determinados casos, ao estilo do que acontece com institutos como a Legítima Defesa e o Estado de Necessidade.
} 
Além disso, ainda atrelam mencionada postura à visão da pena, algo essencialmente voltado para o castigo do infrator, mas se e somente se tais condutas estiverem revestidas de um "alto conteúdo criminal", que será decidido conforme cada caso.

No entanto, embora a insignificância apareça como um critério de interpretação restritiva, bem como critério para a fixação do injusto legal, seguindo a advertência de Prado (2010), a sua configuração é imprecisa, o que, consequentemente, coloca em risco a segurança jurídica.

A questão relacionada às dificuldades da insignificância diz respeito ao próprio referencial a partir do qual essa norma é considerada. Abordando as considerações de Damásio de Jesus (2009, p. 10-11) verificamos que a jurisprudência tem adotado a insignificância em várias situações que abstratamente recebem a reprovação no campo penal, tais como furto de objetos de "valor insignificante", lesão "insignificante" ao Fisco, maus-tratos de "importância mínima", entre outras situações.

No entanto, será que não estaríamos pretendendo atribuir a tais situações uma ofensa anódina, sendo que, a bem da verdade, não seria a própria apreciação uma anódina interpretação por parte dos que acabam decidindo sem critérios legitimadores o que seria ou não insignificante? Ora, "ao juiz não é dado descobrir ou inventar nada, mas sim interpretar os argumentos que lhe são apresentados pelas partes" (CHUEIRI, 2009, p. 261), em contraditório pleno e com efetiva observância da amplitude de defesa no contexto processual penal.

Adotando as orientações de Fernando Armando, a partir das reflexões de Friedrich Müller, "temos que a interpretação no Direito não pode nunca desconsiderar o conjunto das teorias e técnicas interpretativas, bem como todos os princípios que concorrem frente às características fáticas trazidas ao processo de aplicação." (RIBEIRO, 2013, p. 84). Ou seja, o juiz, ao desenvolver sua fundamentação em termos de pronunciamento decisório, não pode se esquecer de que sempre há uma resposta correta para o caso, ainda que marcado por ampla complexidade e poucas normas expressas regulando a temática. Então, seguindo esse raciocínio, para Dworkin (1999; 2005), essa resposta correta estará calcada em um princípio que não aparece como algo metafisicamente apresentado, "mas sim algo que, argumentativamente, se constrói, isto 
é, de maneira articulada e consistente com as práticas jurídicas e sociais da comunidade.” (CHUEIRI, 2009, p. 261).

No âmbito de sua aplicação, vários exemplos na jurisprudência ilustram a amplitude de incidência da insignificância, com destaque para situações que envolvam falsificações de moedas, furtos ${ }^{7}$, crimes tributários, como também casos de lesões corporais e porte de drogas ${ }^{8}$. Diante dessa amplitude de questões, a responsabilidade de sua adequada compreensão aparece com condição de possibilidade para a sua prória aplicaçao, sendo que, quando pensamos em uma "decisão adequada" podemos afirmar que isso traz consigo "muito mais que uma aparente subsunção de norma a fato concreto, sendo diferente também de uma ponderação de valores.” (RIBEIRO, 2013, p. $84)$.

Trivisonno (200-; 2013), ao estudar algumas decisões dos tribunais superiores no campo penal, onde a aplicação da Insignificância foi suscitada, apresenta algumas indagações que refletem o cenário de imprecisão técnica e insegurança jurídica que circundam mencionada formatação normativa. Segundo o autor,

\begin{abstract}
O que é lesão insignificante? Por que não punir condutas quando a lesão é insignificante? Por que é injusto ou por que é ineficaz? Ora, se for por que é injusto, repito, seriam necessárias razões no plano de justificação que demonstrem isso; se for porque é ineficaz seria preciso responder, dentre outras, a seguinte pergunta: não estaria a aplicação do princípio da insignificância prejudicando o efeito de prevenção do Direito Penal, sobretudo quando se considera, como já mostrava Aristóteles (1991), que a virtude ( e também o vício) é um hábito e que portanto a prática de "pequenos" crimes pode levar ao hábito da prática de outros não tão pequenos? (200-, p. 19).
\end{abstract}

O raciocínio desenvolvido diante de tais decisões ${ }^{9}$, mostra uma perigosa postura fundamentadora, por parte dos ministros do STF, no sentido de que, "eles muitas vezes mencionam precedentes sem prestar atenção ao fato de que, no que diz respeito a precedentes, o verdadeiro problema se coloca no estabelecimento da relevância da

\footnotetext{
${ }^{7}$ Existe grande incidência da Insignificância nesse sentido. Para tanto, alguns exemplos aparecem como interessantes: HC 96.496-6, 10/02/2009, relator min. Eros Grau; HC 92.531-6, 10/06/2008, relatora Min. Ellen Gracie.

${ }^{8}$ Considerando a limitação espácio-temporal, a abordagem e crítica da aplicação da Insignificância a tais situações será resultante de estudos posteriores a respeito da temática.

${ }^{9}$ Exemplos desses julgados: HC 84.412-0, 19/10/2004, relator min. Celso de Mello; HC 96.496-6, 10/02/2009, relator min. Eros Grau; HC 92.531-6, 10/06/2008, relatora Min. Ellen Gracie; HC 92.988-5, 10/06/2008, relatora Min. Ellen Gracie.
} 
diferença entre os casos analisados (ALEXY: 1991, 336) ${ }^{10}$.”(TRIVISONNO, 200-, p. $12)$.

A consequência dessa dinâmica é a possível manutenção da ausência de critérios racionalmente justificados para a determinação do que seja uma "lesão insignificante", por exemplo. Desse modo, tais construções, enquanto decisões, resultam marcadas por subjetivismos e arbitrariedades. (TRIVISONNO, 2013).

\section{A questão da Discricionariedade no contexto da Insignificância}

A partir do projeto de construção de um Estado Democrático de Direito, um ponto que merece destaque consiste na identificação de ser, a discricionariedade judicial, um problema, em especial quando a discussão envolve os denominados "hard cases", isto é, os casos difíceis, casos onde, segundo Dworkin, não existe regra estabelecida que prescreva uma decisão. Tais casos, observáveis também no campo do Direito Penal, exigem uma atenção especial do agente julgador, principalmente pelo fato de estarmos em um Estado que adota como pressuposto a produção do direito de forma democrática.

A doutrina e especialmente os tribunais brasileiros, nos últimos anos, têm assumido uma interpretação do direito de maneira muito aproblematizada, alegando que estão desenvolvendo uma interpretação constitucionalmente adequada do Direito Penal. E aqui aparece um grande risco para o Estado Democrático, vez que no Direito não se fala de uma dinâmica interpretativa que seja estanque da aplicação da norma, pois é apenas "nesse momento [que] é possível compreender todo o seu sentido, é ali que se fundamenta sua validade." (LOPES, 2000, p. 109).

Dentre outros problemas possíveis, a pesquisa identifica a questão de decisões que estão fundamentadas em argumentos que mostram, claramente, seu olhar para finalidades, tais como as de cunho político-criminal. Não que tais finalidades não sejam importantes, mas estão deslocadas, em razão da sua natureza.

A utilização gradativa de princípios constitucionais na área penal, perfazendo o sistema de direitos e garantias fundamentais tem alterado essa compreensão refratária ao Estado Democrático. Isso porque, no campo do Direito Penal, a constatação de que a

${ }^{10}$ A obra de Alexy, aqui mencionada, é Theorie der juristischen Argumentation - Die Theorie des rationale Diskurses als Theorie der juristischen Begründung. 
realidade brasileira fixa suas bases interpretativas a partir do dissenso, do pluralismo, tal qual afirma o próprio Texto Constitucional, tem denunciado a insuficiência da adoção de um intelecto pronto e satisfatório a respeito das normas jurídicas. (GALUPPO, 2002).

Por esse motivo, ademais, os casos envolvendo a possível aplicação da Insignificância precisam abarcar, como possibilidade para sua coerente incidência, o trabalho da Literatura Jurídica, afinal, ele "procura lançar pontes entre a teoria e a prática municiando os operadores ${ }^{11}$ do Direito com instrumentos capazes de conduzi-los a respostas pertinentes para os problemas jurídicos, bem fundadas e ao mesmo tempo verificáveis e, na medida do possível ,objetivamente controláveis - daí o papel crucial da argumentação jurídica." (DINIZ; MAIA, 2009, p. 652).

No entanto, a apreciação de julgados realizados pelas turmas do STF, por vezes, consiste em "dizer, às vezes literalmente, às vezes com outras palavras, aquilo que o ministro Celso de Mello ${ }^{12}$ afirmou em seus julgados que versaram sobre a aplicação do princípio da insignificância.” (TRIVISONNO, 200-, p. 12). E mais, existem decisões que apontam apenas expressões "vagas como 'o direito não deve se ocupar do que é insignificante', 'o Direito Penal deve ser mínimo', 'o Direito Penal tem caráter subsidiário' etc. [...]. Mais que isso, elas parecem ser pontos de vista subjetivos que os ministros projetam na Constituição [...]” (TRIVISONNO, 200-, p. 13).

Nesse contexto do não - positivismo, a decisão judicial deve cada vez se adequar às exigências de respeito à construção participada, de modo que não apenas critérios solipsistas do julgador sejam determinantes para o pronunciamento decisório, perfazendo, muitas vezes, a pretensão de justiça. Cada vez mais o "justo é também uma relação construída em cada caso e em cada situação da vida pelos atores da vida em sociedade." (MARÇAL, 2007, p. 38), em um movimento de efetivação do projeto moderno de reconhecimento recíproco e iguais liberdades fundamentais.

No caso jurídico-penal, a adoção de tais ideias se nos apresentam justificadas pelo fato de que essas posturas superam o esquema "sujeito-objeto" e adotam a discussão em sede de uma intersubjetividade. Há plausibilidade nisso, pelo fato segundo o qual, no contexto da hermenêutica, a "superação do esquema sujeito-objeto significou,

\footnotetext{
${ }^{11}$ Apesar de tradicionalmente utilizado, esse termo merece críticas, em razão de sua possível redução e estrita vinculação ao tecnicismo, dinâmica esta perigosa ao contexto de liberdade argumentativa, especialmente sua limitação aos chamados métodos tradicionais de interpretação.

${ }^{12} \mathrm{O}$ ministro Celso de Mello foi o responsável pela eleição dos chamados vetores da Insignificância.
} 
sim, a derrocada da filosofia da consciência, mas não do sujeito da relação (afinal, ele agora se torna sujeito-sujeito)." (STRECK, 2008, p. 159).

Isso aparece claro na adequada compreensão da dimensão processual. Trata-se de um elo que deve existir, "entre hermenêutica e a teoria da argumentação". (RIBEIRO, 2013, p. 184). Ou seja, como estamos diante de um pronunciamento de caráter decisório, a sua construção deve acontecer argumentativamente; logo, "não devem ser apenas as compreensões e pré-compreensões do Juiz que devem conformála." (RIBEIRO, 2013, p. 184).

Por isso, quando o agente julgador e turmas julgadoras estão diante de casos envolvendo a insignificância, nos quais as regras existentes no Sistema Jurídico aparecem como insuficientes, exatamente pela própria pretensão de um Direito Penal, no caso brasileiro, mais voltado para o contexto minimalista, a alternativa tradicional reside em atribuir àqueles legitimados ao julgamento o poder discricionário, "para numa situação de não-direito construir uma norma aplicável ao caso concreto, momento no qual o juiz cria direito novo em face da legislação existente." (DINIZ; MAIA, 2009, p. $653)$.

\section{A adoção da Integridade como estrutura}

O desenvolvimento da tese acima mencionada abre campo para uma importante exigência no momento da Decisão Judicial. Seguindo a linha de Dworkin (1999), não existe abertura para que o julgador "encontre" na literatura aquilo que ele, o julgador, pensa estar ali contido. Tanto assim o é, que sua tarefa é interpretar a história no sentido de sua continuidade e não inventar uma nova e, supostamente, melhor história.

Essa postura hermenêutica faz referência a outro pensador, Hans-Georg Gadamer (1977), uma vez que Dworkin sustenta que os indivíduos estão contidos em uma tradição, sendo que os conceitos presentes nesse contexto aparecem como passíveis de interpretação. Por este motivo, enquanto comunidade "nós compartilhamos as práticas sociais e experiências que esses conceitos figuram." ${ }^{\prime 13}$ (DWORKIN, 2011, p. $06)$.

\footnotetext{
${ }^{13}$ No original em inglês: "we share social practices and experiences in which these concepts figure."
} 
Dworkin, a respeito da Integridade e do deslocamento temporal do direito, dirá que

O direito como integridade, portanto, começa no presente e só se volta para o passado na medida em que seu enfoque contemporâneo assim o determine. Não pretende recuperar, mesmo para o direito atual, os ideais objetivos práticos dos políticos que primeiro o criaram. Pretende, sim, justificar o que eles fizeram [...], em uma história geral digna de ser contada aqui, uma história que traz consigo uma firmação complexa: a de que a prática atual pode ser organizada e justificada por princípios suficientemente atraentes para oferecer um futuro honrado. (DWORKIN, 1999, p.274)

Dessa maneira, a "integridade do direito", algo sustentado na presente pesquisa, inclusive aplicável ao contexto jurídico-penal brasileiro, nos termos desenvolvidos por Dworkin, promove um retorno tanto para o passado, quanto um olhar para o futuro, considerando toda a história institucional já elaborada até aquele momento.

Além disso, a ideia de integridade em Dworkin extrapola a compreensão da consistência, "da ideia de tratar casos similares de maneira similar ou, como ele diz, da mera 'elegância””. (GUEST, 2010, p. 79). Ou que merece destaque é que, quando consideramos a integridade, resulta "fundamental a maneira como as pessoas devem ser tratadas e [Dworkin] considera que os direitos dão origem e limitam as decisões a

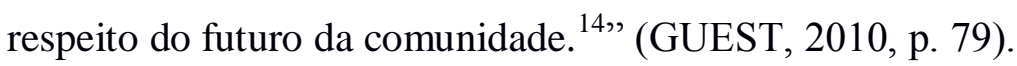

Consequentemente, o direito restará legítimo se permitir a igualdade de intervenção de todos no discurso jurídico, de modo que o provimento final não seja uma questão política e sim uma questão de princípio construída/decidida por uma comunidade de intérpretes/participantes do direito, comunidade na qual a integridade atua possibilitando a ligação das vidas dos cidadãos nos âmbitos moral e político, uma vez que, enquanto comunidade, eles, os cidadãos, aceitam que são governados por princípios comuns.

A partir da contribuição de Ronald Dworkin, observamos que a integridade e a coerência nesse autor são responsáveis, segundo Streck (2008; 2009; 2010) pelo afastamento das possíveis arbitrariedades e decisionismos. Ou seja, uma possível possibilidade para a superação das limitações presentes no contexto positivista.

\footnotetext{
${ }^{14}$ Guest nos fala de uma analogia que pode ser feita para compreendermos a integridade. Trata-se da analogia com a ideia de integridade no âmbito pessoal. "A comunidade deve ser considerada como possuidora de uma personalidade sujeita ao mesmo tipo de crítica moral que fazemos a uma pessoa que não agiu com integridade." (GUEST, 2010, p. 79).
} 
Voltando para o contexto estritamente penal, pertinente se nos apresenta a visão de Gadamer (1977) a respeito do juiz, quando o considera como um intérprete, uma vez que é requisito que a aplicação envolva a compreensão da norma, fazendo com que, no campo do Processo Penal, o juiz atue como verdadeiro garantidor dos direitos do acusado, ao mesmo tempo em que também reconhece os direitos da coletividade, o que, uma vez mais, possibilita a verificação da integridade, especialmente quando a lide alcança ao duplo grau de jurisdição. Este intérprete, juiz ou tribunal, precisa compreender que "a interpretação não é um ato complementar e posterior ao da compreensão, visto que compreender é sempre interpretar, e em consequência a interpretação é a forma explicita da compreensão."15 (tradução livre). (GADAMER, 1977, p. 378).

Mediante a consideração da Integridade no contexto da produção legiferante penal, sua observância alerta os "legisladores [de] que simples barganhas entre justiça e imparcialidade estão erradas [...]." (GUEST, 2010, p. 51). Ou seja, um legislativo que tenha por intuito a criação de seu arcabouço jurídico sem observar a coerência de outros direitos, ou mesmo que auspicie objetivos políticos mediante a realização, portanto, de acordos "arbitrários" que resultem em privilégios para alguns, não observa o tratamento de igual respeito e consideração. O legislador brasileiro, no campo das normas penais às vezes reconhece, prudentemente, a Intervenção Mínima como princípio estruturante do Direito Penal. Como corolários desse princípio, outras normas aparecem como decorrência racional de sua interpretação, dentre as quais, a Insignificância.

Quando a Integridade direciona sua observância para o contexto da decisão judicial, seus destinatários diretos são os juízes, tribunais, como também os advogados, exigindo que todos "façam suas decisões e argumentos se integrarem ao corpo do direito existente." (GUEST, 2010, p. 51). Ou seja, impõe-se que a aplicação das leis, dos conceitos antecipados e das posições dogmáticas, partam da pressuposição de que cada uma dessas encontre justificativa em uma composição mais abrangente.

Com isso, a Integridade

Requer dos nossos juízes, à medida que isso for possível, que tratem do nosso presente sistema de padrões públicos como de um sistema que expressa e

\footnotetext{
${ }^{15}$ No espanhol, "la interpretación no es un acto complementario y posterior al de la comprensión, sino que comprender es siempre interpretar, y en consecuencia la interpretación es la forma explícita de la comprensión."
} 
respeita um conjunto coerente de princípios, e isso de tal maneira que interpretem esses padrões para encontrar padrões implícitos sob os padrões explícitos. (DWORKIN apud GÜNTHER, 2004, p. 410).

Por isso, verificando o grande poder atribuído ao Supremo Tribunal Federal, constata-se que sua responsabilidade também resulta geometricamente aumentada. Tanto que,

Os juízes devem justificar suas sentenças por meio de argumentos de princípios e de integridade, que possam ser criticados pelo meio jurídico e avaliados pela opinião pública, cuja influência deveria ser sentida sempre que os precedentes nomeiam os juízes. (DWORKIN, 2003, p. 173).

É nesse sentido que são pertinentes os desdobramentos dos argumentos desenvolvidos por Habermas (2003), ao refletir a respeito do Estado Democrático de Direito, pelo que podemos perceber de sua afirmação segundo a qual a postura do agente julgador deve aparecer como um dos elementos na dinâmica discursiva, sendo que em conjunto com as partes atuam na pretensão de construir uma decisão resultante do compartilhamento de todos os que estão envolvidos.

Isso certamente faz sentido quando consideramos o Direito firmado no princípio democrático, o que significa dizer que, "por meio da institucionalização de procedimentos estruturados por normas democraticamente justificadas, deve assegurar a participação discursiva dos cidadãos nos processos de tomada de decisões. ${ }^{16 "}$ (COURA, 2004, p. 407).

Considerando o Direito Penal fundado em uma "atitude interpretativa" (DWORKIN, 1985), no campo da decisão judicial, as convicções morais de caráter pessoal do julgador exsurgem. No entanto, ao adotarmos essa visão do Direito, como não apenas uma atitude interpretativa, mas também crítico-reflexiva e fraterna, verificamos que além dessas convicções do agente julgador existem outras mais elevadas, visto que estão relacionadas à própria comunidade. Em termos hermenêuticos, portanto, estas últimas convicções prevalecem no tocante ao peso quando da interpretação do direito. E isso porque tais convicções são legítimas, uma vez que aparecem como resultantes dos princípios que a comunidade, e não de determinado

\footnotetext{
${ }^{16}$ Esse é o sentido pretendido por autores como Jürgen Habermas, como podemos verificar em Between facts and norms.
} 
indivíduo, que legitimado à tomada de decisões adota valores como se fossem uníssonos e compartilhados por todos na sociedade.

Pelas decisões apresentadas, apesar dos problemas ligados à fundamentação, a Insignificância aparece, certamente, como uma norma apta a reforçar o caráter subsidiário do Direito Penal ${ }^{17}$, especialmente mediante a consideração de outro princípio consideravelmente relevante no Direito: a proporcionalidade. Embora uno, o direito aparece estruturado em áreas que elegem seus bens jurídicos passiveis de tutela jurídica. Logo, considerando a proporcionalidade, instancias outras que não a criminal, estariam legitimadas a apurar e decidir a questão envolvendo a prática de comportamentos contrários ao Ordenamento Jurídico, ainda que revestidos da Tipicidade Penal, em seu aspecto formal ${ }^{18}$.

\section{Considerações Finais}

Considerando os argumentos apresentados ao longo do texto, a adequada compreensão da aplicação das normas no contexto penal precisa observar toda a história institucional do Direito Penal, bem como reconhecer que o papel do juiz não é a de ser o protagonista no momento da decisão judicial. Seu papel consiste em reconhecer, nos argumentos apresentados pelas partes, estas sim protagonistas, o fundamento para a construção da resposta correta. Nesse sentido, e com respaldo na determinação do Texto Constitucional, a fundamentação das decisões estaria revestida da adequada racionalidade.

A insignificância, enquanto norma, ainda apresenta imprecisões em sua definição, bem como não tem sido aplicada de forma pacificada pela jurisprudência. As tentativas de sua formatação, não raras vezes, resultam em manifestações aproblematizadas e descompassadas com aquilo que se espera de um Direito Penal democrático.

Uma vez constatada, como ainda presente em muitos pronunciamentos decisórios, o agir discricionário do julgador quando da possível aplicação da Insignificância denuncia a emergência da busca por orientações que direcionam a

\footnotetext{
${ }^{17}$ Ao contrário do que, não raras vezes, pode ser observado no senso comum, ou seja, uma pretensão ao agigantamento do Direito Penal, como uma garantia de "limpar" a sociedade de seus perturbadores ou, para alguns, de seus "inimigos".

${ }^{18}$ A insignificância aparece voltada para o afastamento da Tipicidade Material.
} 
compreensão do Direito de forma a reconhecer e afirmar sua coerência enquanto sistema.

Nesse sentido, a hipótese que sustentava a ideia de Integridade aparece como consideravelmente razoável para afastar a discricionariedade dos julgadores, especialmente se mencionada ideia for observada em suas duas dimensões, é dizer, na Legislação e também na Jurisdição. A razão justificadora desse argumento reside no fato de maior abertura democrática no contexto da legislação e consequente apreciação dos possíveis discursos justificadores da adequada formatação da insignificância. Já no contexto da jurisdição, as hipóteses de cabimento estabelecidas na norma afastariam as imprecisões decisórias, além de permitir uma fundamentação coerente com a missão do Direito Penal no contexto democrático.

\section{Referências}

BITTAR, Eduardo Carlos Bianca. Hans-Georg Gadamer: a experiência hermenêutica e a experiência jurídica. In: BOUCAULT, Carlos E. de Abreu; RODRIGUEZ, José Rodrigo (Org.). Hermenêutica plural. São Paulo: Martins Fontes. 2002.

BLEICHER, Josef. Hermenêutica contemporânea. Lisboa: Edições 70, 2002. BRASIL. Supremo Tribunal Federal. Habeas Corpus $n^{0}$ 100.937. Relator: Ministro Joaquim Barbosa, julgado em 07/12/2010. Diário de Justiça Eletrônico, Brasília, 01 fev. 2011. Disponível em: <http://redir.stf.jus.br/paginadorpub/paginador.jsp? docTP $=$ AC\&docID=618136 $>$. Acesso em: mar. 2015.

BRASIL. Constituição (1988). Constituição da República Federativa do Brasil. Brasília: Senado, 1988.

BRASIL. Supremo Tribunal Federal. Habeas Corpus n ${ }^{\circ}$ 123.108/MG. Relator: Min. Roberto Barroso, julgado em 25/06/2014. Diário de Justiça Eletrônico, Brasília, 02 fev. 2015. Disponível em: <http://www.stf.jus.br/portal/processo/verProcesso Andamento.asp?incidente=4596213>. Acesso em: mar. 2015.

BRASIL. Supremo Tribunal Federal. Habeas Corpus $n^{\circ}$ 84.412-0 SP. Relator: Ministro Celso de Mello, julgado em 19/10/2004. Diário de Justiça Eletrônico, Brasília, 19 nov. 2004.

BRASIL. Supremo Tribunal Federal. Habeas Corpus n ${ }^{\circ}$ 92.463/RS. Relator: Ministro Celso de Mello, julgado em 16/10/2007. Diário de Justiça Eletrônico, Brasília, 31 out. 2007. Disponível em: <http://redir.stf.jus.br/paginadorpub/paginador.jsp?docTP= AC\&docID=492876>. Acesso em: mar. 2015.

BUSATO, Paulo César. O desvalor da conduta como critério de identificação da Insignificância para a aplicação do Princípio da Intervenção Mínima. Revista Sequência. n. 62. Jul 2011. p. 97-111. 
CAPPELLETTI, Mauro. Juízes Legisladores? Trad. Carlos Alberto Alvar de Oliveira. Porto Alegre: Sergio Antonio Fabris Editor, 1999.

CAPEZ, Fernando. Curso de Direito Penal: Parte Geral. 12ed. rev. e atual. São Paulo: Saraiva, 2008.

CHAMON JUNIOR, Lúcio Antônio. Teoria Constitucional do Direito Penal:

contribuições a uma reconstrução da Dogmática penal 100 anos depois. Rio de Janeiro: Lumen Juris, 2006.

CHUEIRI, Vera Karam de. Dworkin, Ronald. (Verbete).

In: BARRETO, Vicente de Paulo (Org.). Dicionário de filosofia do direito. $2^{\mathrm{a}}$ reimpressão. São Leopoldo: Editora Unisinos, 2009. p. 259-263.

COURA, Alexandre de Castro. Limites e possibilidades da tutela jurisdicional no paradigma do Estado Democrático de Direito: para uma análise crítica da "jurisprudência dos valores". In: OLIVEIRA, Marcelo Cattoni de. Jurisdição de Hermenêutica Constitucional no Estado Democrático de Direito. Belo Horizonte: Mandamentos, 2004.

DIAS JUNIOR, José Armando Pontes. A concepção material do tipo penal e a importância da aplicação do princípio da insignificância como causa excludente da tipicidade. Revista Direito e Liberdade - ESMARN: Mossoró, jan-jun/2005, v. 01, n.01, p. 271.284.

DINIZ, Antonio Carlos; MAIA, Antônio Cavalcanti. Pós-positivismo (verbete). In: BARRETO, Vicente de Paulo (coord.). Dicionário de filosofia do direito. $2^{\mathrm{a}}$ reimpressão. Rio de Janeiro: Renovar, 2009.

DWORKIN, Ronald. "The 1984 McCorkle Lecture: Law's ambitions for itself'. Virgínia Law Review, v. 71, n. 02, mar. 1985, p. 173-187.

DWORKIN, Ronald. A matter of principle. Cambridge: Havard University Press, 1978.

DWORKIN, Ronald. Freedom's Law: the moral reading of American Constitution. 3ed. Cambridge: Havard University Press, 1999.

DWORKIN, Ronald. Law's empire. Cambridge: Harvard University Press, 2000.

DWORKIN, Ronald. Levando os direitos a sério. Trad. Nelson Boeira. São Paulo: Martins Fontes, 2002.

DWORKIN, Ronald. O domínio da vida: aborto, eutanásia e liberdades individuais. Jefferson Luis Camargo. (Trad.) São Paulo: Martins Fontes, 2003. 
DWORKIN, Ronald. Levando os direitos a sério. Trad. Nelson Boeira. 2ed. São Paulo: Martins Fontes, 2007.

DWORKIN, Ronald. O Império do Direito. Trad. Jefferson Luiz Camargo. São Paulo: Martins Fontes, 1999.

DWORKIN, Ronald. Uma questão de princípio. 2. ed. São Paulo: Martins Fontes, 2005.

DWORKIN, Ronald. Uma questão de princípio. Trad. Luís Carlos Borges. São Paulo: Martins Fontes, 2000.

DWORKIN, Ronald. Justice for Hedgehogs. Cambridge; Massachusetts: Belknap Press of Harvard University, 2011.

GADAMER, Hans-Georg. Verdad y Método. Tradução por Ana Agud Aparicio y Rafael de Agapino. Salamanca : Sígueme, 1977.

GADAMER, Hans-Georg. Verdade e método: traços fundamentais de uma hermenêutica filosófica. 2. ed. Trad. Flávio Paulo Meurer. Rio de Janeiro: Vozes, 1998.

GADAMER, Hans-Georg. Verdade e método: traços fundamentais de uma hermenêutica filosófica. 2. ed. Tradução de Flávio Paulo Meurer. Rio de Janeiro: Vozes, 1998.

GADAMER, Hans-Georg. Verdad y método. Tradução de Ana Agud Aparicio y Rafael de Agapino. Salamanca: Sígueme, 1977.

GALUPPO, Marcelo Campos. Igualdade e Diferença: Estado Democrático de Direito a partir do pensamento de Habermas. Belo Horizonte: Mandamentos, 2002.

GOMES, Luiz Flavio. Direito penal: parte geral. v. 2. São Paulo: Revista dos Tribunais, 2007.

GOMES, Luiz Flávio. Princípio da Insignificância e outras excludentes de tipicidade. 2. ed. rev. atual. e ampl. São Paulo: RT, 2010.

GRAU, Eros Roberto. Ensaio e discurso sobre a interpretação/aplicação do direito. 4. Ed. São Paulo: Malheiros, 2006.

GRONDIN, Jean. Introdução à hermenêutica filosófica. São Leopoldo: Unisinos, 1999.

GÜNTHER, Klaus. Teoria da argumentação no direito e na moral: justificação e aplicação. São Paulo: Landy, 2004.

GUEST, Stephen. Ronald Dworkin. Trad. Luís Carlos Borges. Rio de Janeiro: Elsevier, 2010. 
HABERMAS, Jürgen. Direito e Democracia: entre faticidade e validade, volume I, 2.ed. Trad. Flávio Beno Siebeneichler. Rio de Janeiro: Tempo Brasileiro, 2003.

HESPANHA, António Manuel. O Caleidoscópio do Direito. O Direito e a Justiça nos dias e no mundo de hoje. Coimbra: Almedina, 2007.

JESUS, Damásio Evangelista de. Direito Penal: Parte Geral. 30. ed. São Paulo: Saraiva, 2009, v. 1.

LALANDE, André. Vocabulário técnico e crítico da filosofia. 3. ed. São Paulo: Martins Fontes, 1999.

LOPES, Ana Maria D'Avila. A hermenêutica Jurídica em Gadamer. Revista de Informação Legislativa: Brasília, a. 37, n. 145, jan./mar. 2000, p. 101-112.

MAÑAS, Carlos Vico. O princípio da insignificância como excludente da tipicidade no Direito Penal. São Paulo: Saraiva, 1994.

MARÇAL, Antônio Cota. Princípio: estatuto, função e usos no direito. In TAVARES, Fernando Horta (org.). Constituição, Direito e Processo. Curitiba: Juruá, 2007, p. 3158.

MAXIMILIANO, Carlos. Hermenêutica e aplicação do Direito. Rio de Janeiro: Forense, 1999.

MORVAN, Patrick. Princípios (Verbete). In: ALLAND, Denis; RIALS, Stéphane. Dicionário de Cultura Jurídica. Trad. Ivone Castilho Benedetti. São Paulo: WMF Martins Fontes, 2012.

PEREIRA, Rodolfo Viana. Hermenêutica filosófica e constitucional. Belo Horizonte: Del Rey, 2001.

PRADO, Luiz Regis. Curso de Direito Penal brasileiro: parte geral, art. $1^{\text {o }}$ a 120.10. ed. atual e ampl. São Paulo: Editora Revista dos Tribunais, 2010.

RAMOS, Gisela Gondin. Princípios Jurídicos. Belo Horizonte: Fórum, 2012.

RIBEIRO, Fernando José Armando. Constitucionalismo e Teoria do Direito. Belo Horizonte: Del Rey, 2013.

ROXIN, Claus. Política criminal e sistema jurídico penal. Rio de Janeiro: 2002.

ROXIN, Claus. Política criminal y sistema del derecho penal. Traducción e introducción de Francisco Muñoz Conde. Barcelona, Bosch, 1972. 
ROXIN, Claus. Problemas fundamentais de direito penal. 3. ed. Trad. Ana Paula dos Santos Luís Natscheradetz, Maria Fernanda Palma, Ana de Figueiredo. Lisboa: Vegas, 1998.

STRECK, Lenio Luiz. Hermenêutica e possibilidades críticas do Direito: ensaio sobre a cegueira positivista. Revista da Faculdade de Direito da UFMG. Belo Horizonte, n. 52, jan-jun/2008, p 127-162.

STRECK, Lenio Luiz. O PROBLEMA DA DECISÃO JURÍDICA EM TEMPOS PÓSPOSITIVISTAS. NEJ - Novos estudos jurídicos. n. 02, vol. 14, $2^{\circ}$ quadrimestre de 2009, p. 03-26.

STRECK, Lenio Luiz. Aplicar a "Letra da Lei" é uma atitude positivista? Revista NEJ - Eletrônica, v. 15, n. 1, p. 158-173, jan./abr. 2010.

TOLEDO, Francisco de Assis. Princípios básicos de direito Penal. São Paulo: Saraiva, 1994.

TRIVISONNO, Alexandre Gomes Travessoni. É coerente a argumentação do Supremo Tribunal Federal nos casos de aplicação do princípio da insignificância (bagatela) em matéria de Direito Penal? (esboço). 200-.

TRIVISONNO, Alexandre Gomes Travessoni. O SUPREMO TR!BUNAL FEDERAL E A ARGUMENTAÇÃO JURIDICA - ANALISE DO PRINCIPIO DA

INSIGNIFICANCIA (BAGATELA) EM MATÉRIA DE DIREITO PENAL. In:

COELHO, Nuno Manuel Morgadinho dos Santos; MAGALHÃES, José Luiz Quadros de (Coord.). O STF e a interpretação da Constituição: casos paradigmáticos em direitos fundamentais. Belo Horizonte: Fórum, 2013. p. 39-58. 